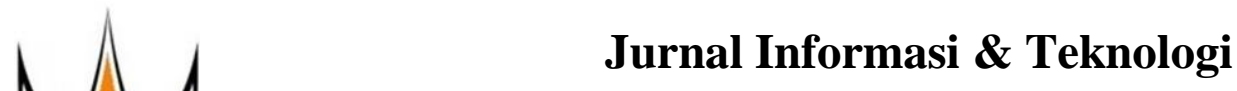

http://www.jidt.org

2019

Vol. $1 \quad$ No. 4

Hal: $18-23$

ISSN: 2714-9730 (electronic)

\title{
Penetapan Penerimaan Besaran Pembiayaan pada KPN Syariah dengan Metode AHP
}

\author{
Salmi Hasni ${ }^{1 凶}$, Gunadi Widi Nurcahyo ${ }^{2}$, Yuhandri Yunus ${ }^{3}$ \\ ${ }^{1,2,3}$ Universitas Putra IndonesiaYPTK Padang \\ sa7mihasni289@gmai1.com
}

\begin{abstract}
The financing approval process for the Al-Ikhlas Sharia Civil Servant Cooperative (KPN) of the Batusangkar State Islamic Institute (IAIN) is still carried out by manual review, making it difficult to receive financing quickly and accurately. As a solution to these problems, we need a decision support system that can help in determining the amount of financial revenue. Analytic Hierarchy Process (AHP) is one of the multi-criteria problem solving models used in this study. The criteria used in determining the amount of financing received at the Al-Ikhlas IAIN Sharia Batusangkar KPN are character, capital, capacity, condition, and collateral. This study produces a weighting matrix of results, with KS as the member who gets the highest score of $95.3 \%$ and can apply for financing with a maximum amount.
\end{abstract}

Keywords: Financing, AHP, Decision Support System, Cooperative, Loan.

\begin{abstract}
Abstrak
Proses persetujuan pembiayaan pada Koperasi Pegawai Negeri (KPN) Syariah Al-Ikhlas Institut Agama Islam Negeri (IAIN) Batusangkar masih dilakukan dengan telaah manual, sehingga sulit melakukan penerimaan pembiayaan secara cepat dan tepat. Sebagai solusi terhadap permasalahan tersebut maka dibutuhkan sebuah sistem pendukung keputusan yang dapat membantu dalam menentukan besaran penerimaan pembiayaan. Analytic Hierarchy Process (AHP) merupakan salah satu model pemecahan masalah yang bersifat multikriteria yang dimanfaatkan dalam penelitian ini. Kriteria yang digunakan dalam penetapan penerimaan besaran pembiayaan pada KPN Syariah Al-Ikhlas IAIN Batusangkar adalah character, capital, capacity, condition, dan collateral. Penelitian ini menghasilkan matriks bobot hasil, dengan $\mathrm{F}$ sebagai anggota yang memperoleh skor tertinggi yaitu 95,3\% dan dapat mengajukan pembiayaan dengan besaran maksimal.
\end{abstract}

Kata kunci: Pembiayaan, AHP, Sistem Pendukung Keputusan, Koperasi, Pinjaman.

(C) 2019 JIdT

\section{Pendahuluan}

Koperasi merupakan suatu badan usaha yang memiliki peranan yang sangat penting dalam menumbuh kembangkan potensi ekonomi rakyat serta mewujudkan kehidupan demokrasi, kebersamaan, kekeluargaan, dan keterbukaan [1]. Koperasi Pegawai Negeri (KPN) Syariah Al-Ikhlas IAIN Batusangkar merupakan salah satu lembaga keuangan non bank yang berbasis syariah. Dalam pelaksanaan operasionalnya KPN Syariah Al- Sistem Pendukung Keputusan merupakan sebuah Ikhlas IAIN Batusangkar sama persis dengan sistem sistem yang mendukung dalam memecahkan masalah perbankan, yaitu dalam menghimpun dan menyalurkan semi-terstruktur dengan cara memberikan informasi dana. Penghimpunan dana yang dilakukan melalui ataupun usulan untuk mendapatkan sebuah keputusan simpanan, tabungan, dan deposito. Sementara dalam tertentu, dengan cara mengorganisir informasi dan penyaluran dana kegiatan yang dilakukan yaitu dengan melibatkan pengguna basis data [2] [3]. Metode AHP melakukan pembiayaan untuk anggota yang membutuhkan.

Saat ini proses persetujuan pembiayaan pada KPN Syariah Al-Ikhlas IAIN Batusangkar dilakukan dengan melalui proses telaah manajer yang masih manual. Namun proses ini memiliki kelemahan yaitu saat manajer tidak berada ditempat dalam jangka waktu tertentu, maka proses realisasi pembiayaan bisa mengalami keterlambatan, karena pengelola yang lain tidak bisa melakukan telaah tersebut. Berdasarkan masalah yang terdapat pada KPN Syariah Al-Ikhlas IAIN Batusangkar, maka dibutuhkan sebuah sistem pendukung keputusan untuk membantu manajer dalam menganalisa proses pembiayaan. digunakan untuk mengambil keputusan yang efektif karena persoalan akan dipecahkan dalam suatu kerangka berfikir yang terorganisir. Dengan metode AHP persoalan yang kompleks dapat disederhanakan dan dipercepat proses pengambilan keputusannya, 
dengan melakukan analisis secara simultan dan Rubber Parts dengan metode Analytic Hierarchy parameter yang saling terintegrasi [4] [5].

Metode AHP mengusulkan cara untuk mengurutkan pemikiran analitis, yang mencakup tiga prinsip dasar, yaitu prinsip membangun hierarki, prinsip prioritas dan prinsip konsistensi logis, di mana untuk mendapatkan penilaian dan penetapan prioritas antara kriteria dibutuhkan preferensi pembuat keputusan melalui pembangunan matriks berpasangan [6].

Process di PT. XYZ menghasilkan tiga faktor yang mempengaruhi keputusan supplier pada komponen hose fuel, yaitu faktor kualitas dengan bobot 0,403 , faktor harga dengan bobot 0,116 , dan faktor produksi dengan bobot tertinggi yaitu sebesar 0,481 [14]. Nguyen, Nguyen, Nguyen, dan Huynh (2016) meneliti tentang Calculating Weight of Social Capital Index Using Analytic Hierarchy Process menghasilkan faktor kepercayaan, Particular Trust dan General Trust Tingkat teratas pada hirarki adalah tujuan atau mendapatkan bobot yang sama yaitu 0,5, sedangkan keputusan, sedangkan tingkat dibawahnya adalah faktor jaringan, Bridging-link mendapatkan bobot yang kriteria. Apabila masih bisa dipecah, maka tingkat terbesar yaitu 0,6544, Bridging 0,2253, Bonding selanjutnya dinamakan sub kriteria, dan seterusnya 0,0798, dan Bonding-link mendapatkan bobot terkecil sampai tingkatan akhir yang merupakan alternatif- yaitu 0,0404 [15].

alternatif yang akan dipilih. Sebagai salah satu metode dalam pengambilan keputusan, pendekatan dengan metode AHP mampu mengurangi bias dari orang yang memiliki potensi untuk menjadi pemilih, dan dapat memeriksa konsistensi penilaian yang diberikan oleh pembuat keputusan sebelum dapat digunakan untuk diterapkan ke masalah, sehingga masalah yang rumit dapat diselesaikan dengan solusi optimal [7] [8].

Dengan menggunakan metode AHP diharapkan dapat membantu pengelola dalam berkomunikasi dan menentukan penetapan besaran jumlah pembiayaan anggota KPN Syariah Al-Ikhlas IAIN Batusangkar yang akan disetujui secara proposional, tepat waktu, dan hasil telaah yang lebih akurat.

\section{Metodologi Penelitian}

Penelitian terdahulu menggunakan metode AHP Metode penelitian ini digunakan sebagai pedoman bagi dilakukan oleh Anjaryati dan Ramdhani (2017) peneliti dalam melaksanakan penelitian yang dilakukan meneliti tentang Sistem Pendukung Keputusan secara sistematik agar hasil yang dicapai tidak Kelayakan Pembiayaan Menggunakan Metode Analytic menyimpang dari tujuan yang telah ditetapkan. Sebuah Hierarchy Process yang menghasilkan suatu sistem penelitian yang baik adalah penelitian yang akurat serta yang dapat menjadi alat bantu manager dalam mampu memberikan nilai guna. Berikut adalah menganalisa hasil survey, untuk meminimalisir jumlah langkah-langkah yang akan dibuat pada penelitian ini.

NPL dan NPF pada periode selanjutnya [9]. Sadinugraha dan Mutiara (2017) meneliti tentang Evaluasi Kinerja Dosen Tetap Menggunakan Metode Analytic Hierarchy Process dan Weighted Product yang menghasilkan rangking setiap dosen secara individual dari yang tertinggi sampai dengan yang terendah berdasarkan sembilan kriteria, sebagai bahan pendukung dan pertimbangan dalam menentukan keputusan-keputusan [10]. Astuti (2016) meneliti tentang Pemilihan Supplier Bahan Baku dengan Metode AHP Studi Kasus PT. Nara Summit Industry, Cikarang menghasilkan hasil akhir perhitungan pemilihan supplier bahan baku yaitu supplier 04 dengan nilai tertinggi sebesar 0.4557 [11]. Muzakir dan Ependi (2019) meneliti tentang Analisis Penggunaan Operator Seluler Menggunakan Metode Analytic Hierarchy Process menghasilkan kriteria bonus, IM3 adalah yang terbaik 0,21712, dan berdasarkan tingkat harga adalah Tri dengan bobot 0,16565 , serta berdasarkan layanan, Simpat merupakan yang lebih baik dengan bobot 0,21311 [12]. Pujadi, Fathurrozi, dan Theresia (2016) meneliti tentang Using Analytical Hierarchy Process for the Decision Support System in Teacher Placement menghasilkan penggunaan metode AHP dapat membantu manajemen puncak dalam memecahkan

masalah yang digunakan sebagai dasar untuk a. Menentukan Kriteria dan Subkriteria mengembangkan aplikasi Penempatan Guru Berbasis DSS [13]. Rimantho, Fathurohman, Cahyadi, dan Sodikun (2017) meneliti tentang Pemilihan Supplier

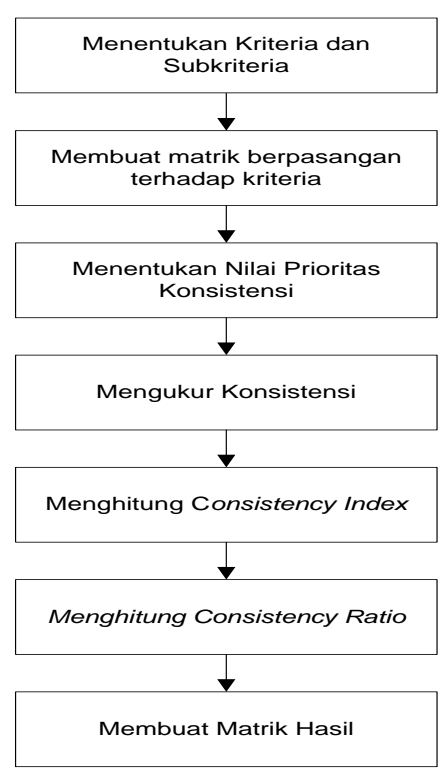

Gambar 1. Kerangka Penelitian

Pada Gambar 1 dapat dilihat urutan proses penelitian penetapan besaran pembiayaan anggota yang tepat menggunakan metode AHP.

Pada penelitian ini digunakan 5 kriteria, 3 subkriteria untuk masing-masing kriteria, dan 15 data sampel 
anggota KPN Syariah Al-Ikhlas IAIN Batusangkar sebagai alternatif, yang dapat dilihat pada struktur hirarki pengujian pada gambar 2 .

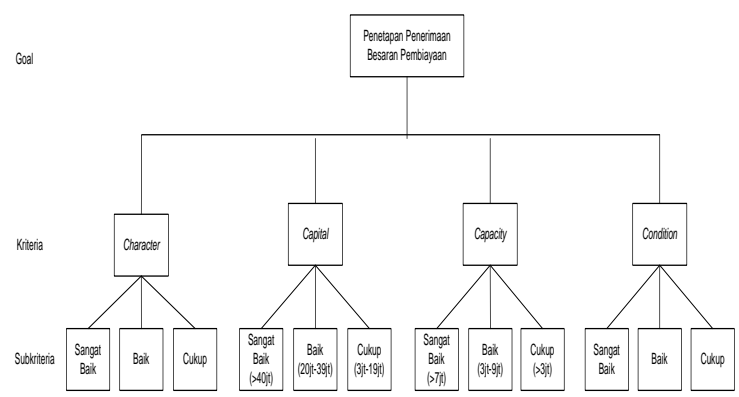

Tabel 1.Skala Penilaian Perbandingan [16]

\begin{tabular}{cl}
\hline $\begin{array}{l}\text { Intensitas } \\
\text { Kepentingan }\end{array}$ & Nilai Kriteria \\
\hline 1 & Kedua elemen sama pentingnya \\
\hline 3 & Elemen yang satu sedikit lebih penting dari pada elemen yang lainnya \\
\hline 5 & Elemen yang satu lebih penting dari elemen yang lainnya \\
\hline 7 & Satu elemen jelas lebih mutlak penting dari pada elemen lainnya \\
\hline 9 & Satu elemen mutlak penting dari pada elemen lainnya \\
\hline $2,4,6,8$ & Nilai-nilai antara dua pertimbangan nilai yang berdekatan \\
\hline Kebalikan & $\begin{array}{l}\text { Jika untuk aktivitas } a \text { mendapatkan satu angka dibanding dengan aktivitas } b, \\
\text { maka } b \text { mempunyai nilai kebalikannya dibanding dengan } a\end{array}$ \\
\hline
\end{tabular}

\section{c. Menentukan Nilai Prioritas Konsistensi}

Nilai-nilai perbandingan relatif dari seluruh alternatif kriteria bisa disesuaikan dengan Judgement yang telah ditentukan untuk menghasilkan bobot dan prioritas. Prioritas ini ditentukan berdasarkan pandangan para pakar atau pihak-pihak terkait yang berkompeten terhadap pengambilan keputusan.

d. Mengukur Konsistensi

Dalam pembuatan keputusan, penting untuk g. Membuat Matriks Hasil mengetahui seberapa baik konsistensi yang ada karena Setelah dilakukan analisa model dengan perhitungan kita tidak menginginkan keputusan berdasarkan kriteria dan subkriteria, hasilnya dituangkan dalam pertimbangan dengan konsistensi yang rendah. Hal-hal matriks hasil yang akan dijadikan acuan dalam yang dilakukan dalam langkah ini adalah sebagai menentukan jumlah maksimal besaran pembiayaan berikut: anggota.

a. Kalikan setiap nilai pada kolom pertama dengan 3. Hasil dan Pembahasan prioritas relatif elemen pertama, nilai pada kolom kedua dengan prioritas relatif elemen kedua dan seterusnya.

b. Jumlahkan setiap baris.

c. Hasil dari penjumlahan baris dibagi dengan elemen prioritas relatif yang bersangkutan.

d. Jumlahkan hasil bagi di atas dengan banyaknya elemen yang ada, hasilnya disebut $\lambda$ maks

e. Menghitung Consistency Index

$$
C I=\frac{(\text { dmaks }-n)}{n} \ldots=\ldots(1]
$$

Dimana $n=$ banyaknya elemen $n$

f. Menghitung Consistency Ratio

$C R=\frac{C I}{C R}=\mathrm{m}-\mathrm{m}-(2)$

Di mana CR = Consistency Ratio
Penetapan jumlah besaran pembiayaan anggota pada KPN Syariah Al-Ikhlas IAIN Batusangkar memiliki tahapan sebagai berikut:

\subsection{Menentukan Kriteria dan Subkriteria}

Kriteria yang dipertimbangkan pada penelitian ini terdiri dari lima kriteria yaitu Character, Capital, Capacity, Condition, dan Collateral. Masing-masing kriteria memiliki subkriteria yang dapat dilihat pada Tabel 2:

Tabel 2. Kriteria dan Subkriteria

\begin{tabular}{cll}
\hline No & Kriteria & Subkriteria \\
\hline 1 & Character $(\mathrm{K} 1)$ & Sangat Baik, Baik, Cukup \\
\hline 2 & Capital $(\mathrm{K} 2)$ & Sangat Baik (>40jt), Baik (20jt-39jt), Cukup (3jt-19jt) \\
\hline 3 & Capacity (K3) & Sangat Baik (>7jt), Baik (3jt-7jt), Cukup (<3jt) \\
\hline 4 & Condition $(\mathrm{K} 4)$ & Sangat Baik, Baik, Cukup \\
\hline 5 & Collateral $(\mathrm{K} 5)$ & Baik, Cukup, Tidak \\
\hline
\end{tabular}

Jurnal Informasi \& Teknologi Vol. 1 No. 4 (2019) 18-23 
\begin{tabular}{lll}
\hline No & Kriteria & Subkriteria \\
\hline
\end{tabular}

\subsection{Membuat Matriks Berpasangan Terhadap Kriteria}

Berdasarkan perbandingan kriteria, maka akan menghasilkan matriks berpasangan terhadap kriteria yang didapatkan dari penilaian perbandingan antara satu kriteria dengan kriteria yang lain. Hasil penilaian bisa dilihat dalam Tabel 3, di mana pada tabel angka 1,000 dapat ditempatkan secara diagonal pada pojok kiri atas sampai dengan pojok kanan bawah, untuk menandakan bahwa perbandingan terhadap dua hal yang sama adalah 1 atau equal preferred. Sedangkan angka 9,000 pada kolom capacity baris character menunjukkan character mutlak lebih penting dibandingkan dengan capacity. Angka 0,111 pada kolom character baris capacity merupakan hasil perhitungan 1/nilai pada kolom capacity baris Nilai pada kolom prioritas diperoleh dari nilai pada character (9,000). Angka yang lain diperoleh dengan kolom jumlah dibagi dengan jumlah kriteria, dalam hal cara yang sama, yaitu berdasarkan hasil pembagian ini ada 5 kriteria. pada tiap nilai pada masing-masing tabel.

Tabel 4. Matriks Nilai Kriteria

\begin{tabular}{rrrrrrrc}
\hline & K1 & K2 & K3 & K4 & K5 & Jumlah & Prioritas \\
\hline K1 & 0,750 & 0,875 & 0,523 & 0,409 & 0,375 & 2,932 & 0,586 \\
\hline K2 & 0,083 & 0,097 & 0,407 & 0,318 & 0,292 & 1,197 & 0,239 \\
\hline K3 & 0,083 & 0,014 & 0,058 & 0,227 & 0,208 & 0,591 & 0,118 \\
\hline K4 & 0,083 & 0,014 & 0,012 & 0,045 & 0,125 & 0,279 & 0,056 \\
\hline K5 & 0,083 & 0,014 & 0,012 & 0,015 & 0,042 & 0,166 & 0,033 \\
\hline
\end{tabular}

Matriks pada Tabel 5 dibuat dengan mengalikan nilai 3.5. Menghitung Consistency Index prioritas pada Tabel 4 dengan nilai baris pada matriks perbandingan berpasangan (Tabel 3).

Tabel 5. Matriks Penjumlahan Setiap Baris

\begin{tabular}{ccccccc}
\hline & K1 & K2 & K3 & K4 & K5 & Jumlah \\
\hline K1 & 0,586 & 2,155 & 1,064 & 0,503 & 0,298 & 4,606 \\
\hline K2 & 0,065 & 0,239 & 0,827 & 0,391 & 0,232 & 1,755 \\
\hline K3 & 0,065 & 0,034 & 0,118 & 0,279 & 0,166 & 0,663 \\
\hline K4 & 0,065 & 0,034 & 0,024 & 0,056 & 0,099 & 0,278 \\
\hline K5 & 0,065 & 0,034 & 0,024 & 0,019 & 0,033 & 0,175 \\
\hline
\end{tabular}

\subsection{Mengukur Konsistensi}

Rasio konsistensi diperoleh dari hasil penjumlahan perhitungan rasio konsistensi kriteria. matriks penjumlahan setiap baris pada masing-masing kriteria/subkriteria ditambah dengan nilai prioritas setiap kriteria/subkriteria pada matriks nilai.

Tabel 6. Perhitungan Rasio Konsistensi

\begin{tabular}{llll}
\hline & Jumlah Per Baris & Prioritas & Hasil \\
\hline Character & 4,606 & 0,586 & 5,193 \\
\hline Capacity & 1,755 & 0,239 & 1,994 \\
\hline Capital & 0,663 & 0,118 & 0,781 \\
\hline Condition & 0,278 & 0,056 & 0,334 \\
\hline Collateral & 0,175 & 0,033 & 0,208 \\
\hline \multicolumn{2}{c}{ Jumlah } & 8,510 \\
\hline
\end{tabular}

Dari tabel 6 diperoleh nilai-nilai sebagai berikut:

Jumlah nilai hasil $=8,510$

jumlah kriteria $(\mathrm{n})=5$

$\lambda$ maks $=$ jumlah $/ \mathrm{n}=8,510 / 5=1,702$
Setelah mendapatkan nilai $\lambda$ maks dari kriteria dan masing-masing sub kriteria, langkah selanjutnya adalah mencari nilai Consistency Index (CI) Kriteria.

Tabel 3. Matriks Perbandingan Berpasangan Kriteria

\begin{tabular}{cccccc}
\hline & $\mathrm{K} 1$ & $\mathrm{~K} 2$ & $\mathrm{~K} 3$ & $\mathrm{~K} 4$ & $\mathrm{~K} 5$ \\
\hline $\mathrm{K} 1$ & 1,000 & 9,000 & 9,000 & 9,000 & 9,000 \\
\hline $\mathrm{K} 2$ & 0,111 & 1,000 & 7,000 & 7,000 & 7,000 \\
\hline $\mathrm{K} 3$ & 0,111 & 0,143 & 1,000 & 5,000 & 5,000 \\
\hline K4 & 0,111 & 0,143 & 0,200 & 1,000 & 3,000 \\
\hline K5 & 0,111 & 0,143 & 0,200 & 0,333 & 1,000 \\
\hline Jumlah & 1,444 & 10,429 & 17,400 & 22,333 & 25,000 \\
\hline
\end{tabular}

3.3. Menentukan Nilai Prioritas Konsistensi

Nilai baris tiap kolom matriks kriteria = Nilai baris tiap kolom matriks perbandingan berpasangan / Jumlah $\mathrm{CI}=((\lambda$ maks $-\mathrm{n}) / \mathrm{n})=(1,702-5) / 5=-0,660$ 3.6. Menghitung Consistency Ratio

Perhitungan ini digunakan untuk memastikan bahwa nilai Consistency Ratio $(\mathrm{CR})<=0,1$. Jika ternyata nilai CR lebih besar dari 0,1, maka matriks perbandingan berpasangan harus diperbaiki. Berikut adalah $\mathrm{CR}=\mathrm{CI} / \mathrm{IR}=-0,660 / 1,12=-0,589$

Oleh karena $\mathrm{CR}<0,1$, maka rasio konsistensi dari perhitungan tersebut bisa diterima.

\subsection{Menghitung Matriks Hasil}

Setelah dilakukan analisa model dengan perhitungan kriteria dan subkriteria, hasilnya dituangkan dalam matriks hasil yang terlihat dalam Tabel 7.

Tabel 7. Matriks Hasil Prioritas

\begin{tabular}{lllll}
\hline K1 & K2 & K3 & K4 & K5 \\
\hline 0,586 & 0,239 & 0,118 & 0,056 & 0,586 \\
\hline SB & SB & SB & SB & B \\
\hline 1,000 & 1,000 & 1,000 & 1,000 & 1,000 \\
\hline B & B & B & B & C \\
\hline 0,355 & 0,448 & 0,500 & 0,451 & 0,355 \\
\hline C & C & C & C & T \\
\hline
\end{tabular}




\begin{tabular}{lllll}
\hline 0,189 & 0,197 & 0,250 & 0,188 & 0,189 \\
\hline
\end{tabular}

Nilai 0,208 pada kolom character baris A pada tabel 8 diperoleh dari nilai A untuk character, yaitu baik dengan prioritas 0,355 dikalikan dengan prioritas character sebesar 0,586 (Tabel 7). Kolom total pada Tabel 8 diperoleh dari penjumlahan pada masingmasing barisnya. Nilai total inilah yang dipakai sebagai dasar untuk menetapkan besaran penerimaan

Tabel 4. Matriks Nilai Kriteria

\begin{tabular}{llllllll}
\hline No. & Nama & Character & Capital & Capacity & Condition & Collateral & Total \\
\hline 1 & A & 0,208 & 0,059 & 0,107 & 0,011 & 0,009 & 0,394 \\
\hline 2 & B & 0,586 & 0,059 & 0,107 & 0,056 & 0,009 & 0,818 \\
\hline 3 & C & 0,586 & 0,118 & 0,107 & 0,056 & 0,009 & 0,877 \\
\hline 4 & D & 0,586 & 0,118 & 0,107 & 0,011 & 0,009 & 0,831 \\
\hline 5 & E & 0,111 & 0,059 & 0,107 & 0,011 & 0,009 & 0,296 \\
\hline 6 & F & 0,586 & 0,118 & 0,239 & 0,025 & 0,009 & 0,978 \\
\hline 7 & G & 0,208 & 0,030 & 0,047 & 0,025 & 0,009 & 0,319 \\
\hline 8 & H & 0,208 & 0,030 & 0,047 & 0,025 & 0,009 & 0,319 \\
\hline 9 & I & 0,111 & 0,030 & 0,047 & 0,025 & 0,009 & 0,222 \\
\hline 10 & J & 0,111 & 0,118 & 0,107 & 0,011 & 0,009 & 0,355 \\
\hline 11 & K & 0,586 & 0,059 & 0,107 & 0,011 & 0,021 & 0,784 \\
\hline 12 & L & 0,208 & 0,030 & 0,047 & 0,025 & 0,009 & 0,319 \\
\hline 13 & M & 0,208 & 0,059 & 0,047 & 0,025 & 0,009 & 0,349 \\
\hline 14 & N & 0,208 & 0,059 & 0,107 & 0,025 & 0,009 & 0,408 \\
\hline 15 & O & 0,208 & 0,059 & 0,107 & 0,056 & 0,033 & 0,463 \\
\hline
\end{tabular}

Jumlah besaran pembiayaan anggota yang akan disetujui dikelompokkan menjadi 4 bagian, yaitu jika anggota yang memperoleh nilai total sebesar 0,100 (10 $\%$ s.d. $0,250 \quad(25 \%)$ maka mendapatkan besaran pembiayaan maksimal sebesar Rp 30.000.000,-Anggota yang memperoleh nilai akhir dengan jumlah $0,251(25,1 \%)$ s.d. 0,500 (50\%) maka mendapatkan besaran pembiayaan maksimal sebesar Rp 50.000.000,. Anggota yang memperoleh nilai akhir dengan jumlah $0,501(50,1 \%)$ s.d. 0,750 (75\%) maka mendapatkan besaran pembiayaan maksimal sebesar Rp 100.000.000,-. Sedangkan untuk anggota yang memperoleh nilai akhir dengan jumlah $0,751(75,1 \%)$ s.d. 0,1000 (100 \%) maka mendapatkan besaran pembiayaan maksimal sebesar Rp 150.000.000,-.

\section{Kesimpulan}

Penelitian ini menghasilkan matriks bobot hasil, dengan F sebagai anggota yang memperoleh skor tertinggi yaitu 95,3 \% dan dapat mengajukan pembiayaan dengan besaran maksimal. Penelitian ini akan sangat membantu pengelola dalam menetapkan besaran penerimaan pembiayaan pada KPN Syariah IAIN Batusangkar.

\section{Daftar Rujukan}

[1] Rahmawati, E., Retnasari T., \& Arifianto R. (2016). Sistem Informasi Simpan Pinjam Koperasi Berbasis WEB (Studi Kasus: Koperasi Sejahtera PT. Induro Internasional Tanggerang. Jurnal Teknik Komputer AMIK BSI. 2(2), 83-88. http://dx.doi.org/10.31294/jtk.v2i2.2239

[2] Putra, P. A. S., \& Wirawan, I. M. A. (2016). Pengembangan Sistem Pendukung Keputusan Penerimaan Siswa Baru di SMA Negeri 1 Seririt dengan Metode Simple Additive Weighting pembiayaan anggota KPN Syariah Al-Ikhlas IAIN

Batusangkar yang akan disetujui.

(SAW) Dan Metode Analytical Hierarchy Process (AHP). Kumpulan Artikel Mahasiswa Pendidikan Teknik Informatika, 5(1), 1-11. http://dx.doi.org/10.23887/karmapati.v5i1.6633

[3] Pujiati, D. R. (2011). Sistem Pendukung Keputusan Evaluasi Kinerja Dosen Berbasis Analytical Hierarchy Process (AHP). Expert. Jurnal Sistem Informasi, 2(2)

[4] Irfansyah, P. (2016). Sistem Pendukung Keputusan Pemilihan Asuransi Analytic Hierarchy Process. 9(3), 274-282. http://dx.doi.org/10.30998/faktorexacta.v9i3.878

[5] Na'am, J. (2017). Sebuah Tinjauan Penggunaan Metode Analythic Hierarchy Process (AHP) dalam Sistem Penunjang Keputusan (SPK) pada Jurnal Berbahasa Indonesia. Jurnal Mediasisfo, 11(2), 888-895.

[6] Guerrero-Liquet, G. C., Sánchez-Lozano, J. M., GarcíaCascales, M. S., Lamata, M. T., \& Verdegay, J. L. (2016). Decision-making for risk management in sustainable renewable energy facilities: A case study in the Dominican Republic. Sustainability (Switzerland), 8(5), 455. https://doi.org/10.3390/su8050455

[7] Narabin, S., \& Boonjing, V. (2016). Selecting students to a dormitory using AHP. 2016 13th International Joint Conference on Computer Science and Software Engineering, JCSSE 2016. https://doi.org/10.1109/JCSSE.2016.7748898

[8] Meesawad, S., Prapawat, S., \& Wongwirat, O. (2017). Choosing industrial wireless sensor by using analytic hierarchy process. Proceedings of 2016 8th International Conference on Information Technology and Electrical Engineering: Empowering Technology for Better Future, ICITEE 2016, 610. https://doi.org/10.1109/ICITEED.2016.7863274

[9] Anjaryanti, S. R., \& Ramdhani, Y. (2017). Sistem Pendukung Keputusan Mahasiswa Berprestasi Menggunakan Metode Analytical Hierarchy Process. Jurnal Informatika, 4(1), 82-93. http://dx.doi.org/10.31311/ji.v4i1.1697

[10] Sudinugraha, T., \& Mutiara, A. B. (2017). Evaluasi Kinerja Dosen Tetap Menggunakan Metode Analytical Hierarchy Process dan Weighted Product. METIK Jurnal, 1(2), 65-69. 
[11] Astuti, P. (1993). Pemilihan Supplier Bahan Baku Dengan Metode Ahp Study Kasus Pt. Nara Summit Industry Cikarang. IJCIT (Indonesian Journal on Computer and Information Technology), 1(2), 39-48.

[12] Muzakir, A., \& Ependi, U. (2019). Analysis of the Use of Cellular Operators Using the Analytic Hierarchy Process Method. Journal of Information Systems and Informatics, 1(1), 29-38. https://doi.org/10.33557/journalisi.v1i1.5

[13] Pujadi, T., Fathurrozi, A., \& Theresia, S. (2017). Using Analytical Hierarchy Process for the decision support system in teacher placement. Proceedings of 2016 International Conference on Information Management and Technology, ICIMTech 2016, (November), 182-187. https://doi.org/10.1109/ICIMTech.2016.7930326

[14] Rimantho, D., Fathurohman, F., Cahyadi, B., \& Sodikun, S. (2017). Pemilihan Supplier Rubber Parts Dengan Metode Analytical Hierarchy Process Di PT.XYZ. Jurnal Rekayasa Sistem Industri, 6(2), 93. https://doi.org/10.26593/jrsi.v6i2.2094.93-104

[15] Van Nguyen, P., Nguyen, P. T., Nguyen, Q. L. H. T. T., \& Huynh, V. D. B. (2016). Calculating weights of social capital index using analytic hierarchy process. International Journal of Economics and Financial Issues, 6(3), 1189-1193. 